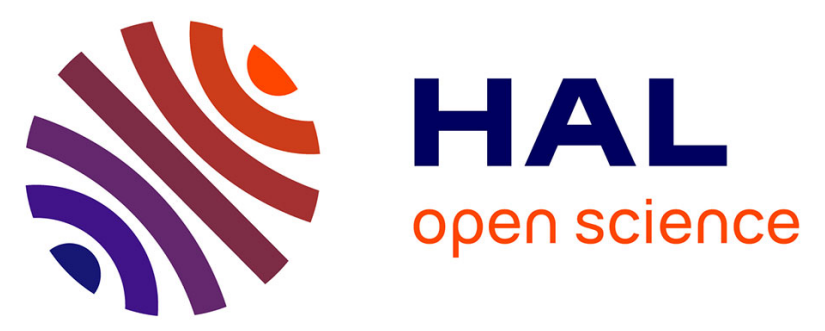

\title{
Simultaneous Influence of Static Load and Temperature on the Electromechanical Signature of Piezoelectric Elements Bonded to Composite Aeronautic Structures
}

Marc Rébillat, Mikhail Guskov, Etienne Balmès, Nazih Mechbal

\section{- To cite this version:}

Marc Rébillat, Mikhail Guskov, Etienne Balmès, Nazih Mechbal. Simultaneous Influence of Static Load and Temperature on the Electromechanical Signature of Piezoelectric Elements Bonded to Composite Aeronautic Structures. Journal of Vibration and Acoustics, 2016, 138 (6), pp.1-6. 10.1115/1.4034375 . hal-01382898

\section{HAL Id: hal-01382898 \\ https://hal.science/hal-01382898}

Submitted on 17 Oct 2016

HAL is a multi-disciplinary open access archive for the deposit and dissemination of scientific research documents, whether they are published or not. The documents may come from teaching and research institutions in France or abroad, or from public or private research centers.
L'archive ouverte pluridisciplinaire HAL, est destinée au dépôt et à la diffusion de documents scientifiques de niveau recherche, publiés ou non, émanant des établissements d'enseignement et de recherche français ou étrangers, des laboratoires publics ou privés. 


\title{
Simultaneous influence of static load and temperature on the electromechanical signature of piezoelectric elements bonded to composite aeronautic structures
}

\author{
Marc Rebillat, Mikhail Guskov, Etienne Balmes, Nazih Mechbal \\ PIMM Laboratory \\ Arts et Metiers / CNRS / CNAM \\ Paris, France \\ Email: marc.rebillat@ensam.eu
}

\begin{abstract}
Electromechanical (EM) signature techniques have raised a huge interest in the structural health monitoring community. These methods aim at assessing structural damages and sensors degradation by analyzing the EM responses of piezoelectric components bonded to aeronautic structures. These structures are subjected simultaneously to static loads and temperature variations that affect the metrics commonly used for damage detection and sensor diagnostics. However, the effects of load and temperature on these metrics have mostly been addressed separately. This paper presents experimentations conducted to investigate the simultaneous influence of static load and temperature on these metrics for two kinds of piezoelectric elements (PZT: lead zirconate titanate, and MFC: macro fiber composite) bonded on sandwich composite materials, for the full range of real-life conditions encountered in aeronautics. Results obtained indicate that both factors affect the metrics in a coupled manner in particular due to the variations of the mechanical properties of the bonding layer when crossing its glass transition temperature. Furthermore, both piezoelectric elements globally behave similarly when subjected to temperature variations and static loads. Simultaneous accounting of both temperature and static load is thus needed in practice in order to design reliable structural health monitoring systems based on these metrics.
\end{abstract}

\section{Introduction}

In the past decades, electromechanical (EM) signature techniques have gained importance in the structural health monitoring community [1-4]. The EM signature technique consists of measuring the EM signature (real or imaginary part of the impedance or admittance as a function of frequency) of a piezoelectric sensor which is mounted on a host structure in order to pinpoint incipient damages that may appear on the structure (damage detection) or to detect any defect on the sensor itself (sensor diagnostics). In an aeronautic context, temperature variations as well as static loads induced on the structure during a flight can both be very important. Experiments have been carried out that focused on temperature [5-17] or static loads [18-22], but rarely simultaneously [23-26]. Regarding temperature effects, it has been observed that the effect of temperature changes consists of a shift of the piezoelectric resonance frequencies. It has also been shown that higher temperature increases the apparent capacitive value of the bonded piezoelectric patch. Regarding the effect of static loads, it has been shown that the magnitude of the peaks and valleys of the EM signature decreases with an increase of applied loads and that natural frequencies shift proportionally with the applied load. Regarding the influence of both temperature and static loads, a strategy has been designed by Lim et al. [23] to compensate for their effects and Zhu et al. [24,25] and Xu et al. [26] analyzed experimentally both effects, but in a separate manner.

This paper thus presents experiments conducted to investigate the coupled influence of mechanical load and temperature on the associated damage detection and sensor self diagnostics metrics for two kinds of piezoelectric components (PZT: lead zirconate titanate, and MFC: macro fiber composite) that have been surface-mounted on sandwich composite materials. The glass transition frequency of the bonding layer has also been crossed in order to assess experimentally its importance. And in order to support the industrial deployment of this technique, special care has been taken to cover the full range of real-life conditions encountered by aircraft components. 


\section{Electromechanical (EM) signatures and associated metrics}

The terminology "electromechanical signature" of piezo-electric elements encompasses different physical meanings depending on the application goal: damage detection or sensor diagnostics. Here, the impedance $Z(f)$ and its inverse, the admittance $Y(f)$, are defined in Eq. (1) as transfer functions between voltage $V(f)$ applied to the piezo-electric element and the resulting current $I(f)$. In this paper $f$ denotes the frequency in Hertz.

$$
Z(f)=\frac{1}{Y(f)}=\frac{V(f)}{I(f)}=R(f)+i X(f)=\frac{1}{G(f)+i B(f)}
$$

The resistance $R(f)$ and reactance $X(f)$ are defined as the real and imaginary parts of the impedance $Z(f)$. Similarly, the conductance $G(f)$ and susceptance $B(f)$ are defined as the real and imaginary parts of the admittance $Y(f)$.

The most common metrics for damage detection using the EM signature are based on the analysis of the resistance $R(f)[1,3,27,28]$. Let $R_{\text {ref }}(f)$ be the resistance in the reference healthy case and $R_{\text {unk }}(f)$ the resistance in the current unknown state. A standard metric that is commonly used for damage detection is the "root mean square deviation" (RMSD) computed between the frequencies $f_{a}$ and $f_{b}$ as in Eq. (2). It is expected that this metric will increase with the apparition of a damage in the vicinity of the piezo-electric element.

$$
\mathrm{RMSD}=\sqrt{\int_{f_{a}}^{f_{b}}\left[\frac{R_{\mathrm{ref}}(f)-R_{\mathrm{unk}}(f)}{R_{\mathrm{ref}}(f)}\right]^{2} d f}
$$

Common sensor diagnostics procedures using the EM signature are based on the analysis of the susceptance $B(f)[2$, 11,29-31]. Let $B_{\text {ref }}(f)$ be the susceptance in the reference healthy case and $B_{\text {unk }}(f)$ the susceptance in the current unknown state. A metric that is used for sensor diagnostics is the "static capacity" $C^{\mathrm{s}}$ computed for the reference and the unknown states between the frequencies $f_{a}$ and $f_{b}$ as in Eq. (3). This metric is expected to increase with a debonding of the piezoelectric element and to decrease with its breakage, thus allowing to differentiate between both effects.

$$
C^{\mathrm{s}}=\frac{1}{f_{b}-f_{a}} \int_{f_{a}}^{f_{b}} \frac{B(f)}{2 \pi f} d f
$$

\section{Experimental method}

The testing was performed on identical specimens of honeycomb carbon-fiber-reinforced polymer (CFRP) sandwich structured beams $\left(L \times l \times h=300 \times 100 \times 31.5 \mathrm{~mm}^{3}\right)$ typically used to build aircraft engine nacelles. Two different piezoelectric components were bonded to the beam surfaces: one MFC (Micro-fiber Composite, type P2, $L \times l \times h=$ $28 \times 14 \times 0.3 \mathrm{~mm}^{3}$ ) from Smart Materials and one PZT (Lead Zirconate Titanate, diameter $25 \mathrm{~mm}$ ) from Noliac. The bi-component epoxy glue 302-3M from Epoxy Technology was used to bond both piezoelectric elements to the sandwich beams. The bonding process consists of $24 \mathrm{~h}$ drying at ambient temperature and under pressure $(\simeq 0.8$ bars). According to the manufacturer data sheet this glue can be used between $-55^{\circ} \mathrm{C}$ and $175^{\circ} \mathrm{C}$ and with a glass transition temperature of $55^{\circ} \mathrm{C}$, as verified by a differential scanning calorimetry test. In practice, this means that the glue modulus will decrease drastically above $55^{\circ} \mathrm{C}$.

Considered structural load condition corresponds to compressive strains varying in the range $\varepsilon \in\left[0, \varepsilon_{0}\right]$ with $\varepsilon_{0}=-0.2 \%$ maximum allowable strain level. Four point bending tests were performed with a mechanical test machine in order to generate compressive strain in the zone of piezoelectric transducers application, as shown in Fig. 1(a) and 1(b). Tests were made in an enclosure where the temperature can be controlled. Liquid nitrogen was used to reach the coldest temperatures. Thermocouples were used to determine the exact temperature at the surface of the specimens. The experimental setup used to realize the impedance measurements consists of a high speed data acquisition system, a waveform generator, a circuit able to measure both the voltage applied to the piezoelectric element and the resulting current [1,3,32], and a laptop. The whole experimental setup can be seen on Fig. 1(c). The input voltage applied to the piezoelectric elements is a $250 \mathrm{~ms}$ long linear sine sweep having energy between $1 \mathrm{kHz}$ and $400 \mathrm{kHz}$.

The experimental procedure developed here aimed at covering the environmental conditions encountered in real life by aircraft structures. Temperature varied from $-60^{\circ} \mathrm{C}$ to $120^{\circ} \mathrm{C}$ by steps of $30^{\circ} \mathrm{C}$. For each temperature line static loads from corresponding to $\varepsilon / \varepsilon_{0}=\{0,0.2,0.4,0.6,0.8,1\}$ are applied. For each combination of static load and temperature, the EM impedance was acquired three times after temperature stabilisation of the specimen. For each temperature, the EM 


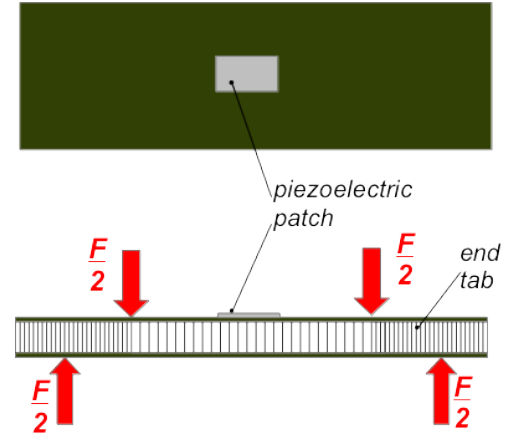

(a) Bending load configuration

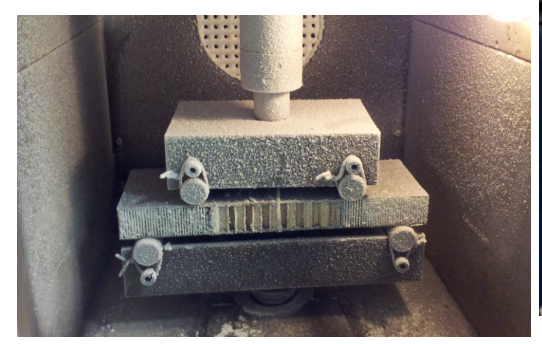

(b) Bending test at $-60^{\circ} \mathrm{C}$.

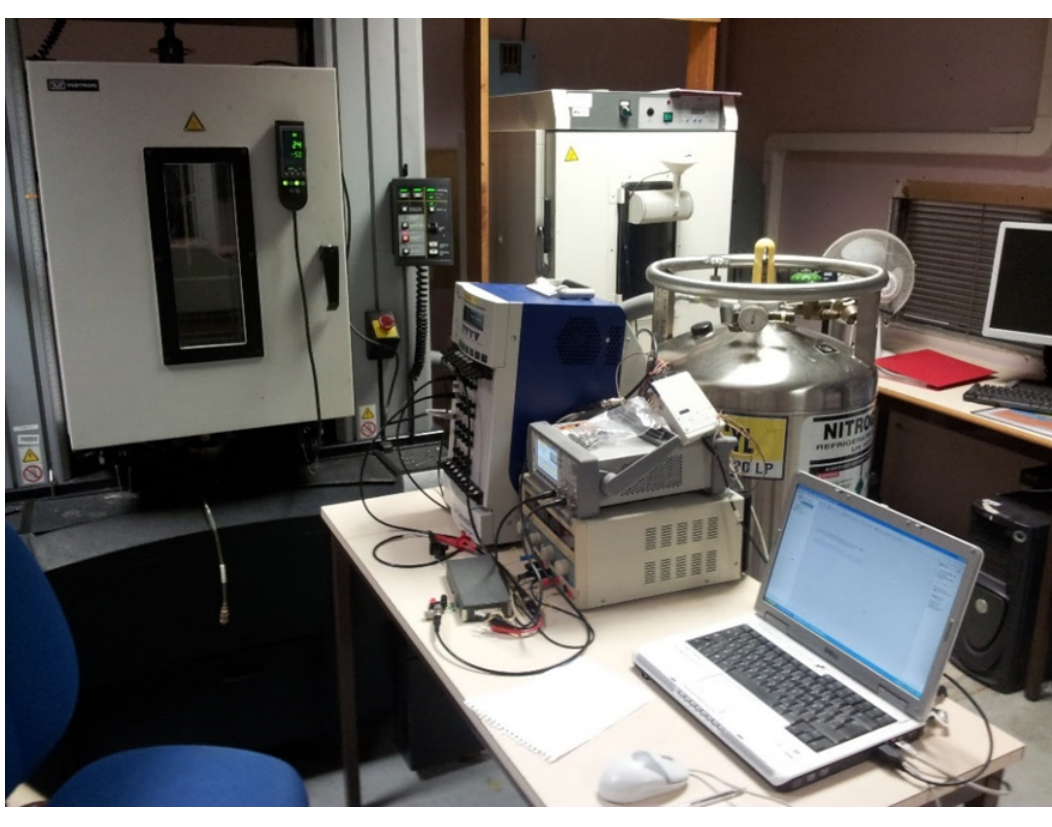

(c) Experimental setup overview

Fig. 1. Experimental equipment

impedance of the free piezoelectric elements was also acquired three times. The three impedances measured experimentally for each case were afterward averaged in the frequency domain in order to increase the signal to noise ratio.

Additional experiments were carried out to compare the influence of temperature and static load to the influence of the presence a damage. These experiments were all conducted at room temperature, i.e. at $28^{\circ} \mathrm{C}$ and without any applied load $\left(\varepsilon / \varepsilon_{0}=0\right)$. Damage is simulated by means of two added masses $(5.8 \mathrm{~g}$ and $11.8 \mathrm{~g})$ that are lying on the specimens respectively at $1 \mathrm{~cm}, 2 \mathrm{~cm}$, and $3 \mathrm{~cm}$ from the right border of the considered piezoelectric element (PZT or MFC). In order to compare the influence of temperature and loading to the influence of sensor degradation, two extreme cases are considered: perfectly bonded and free piezoelectric element, still at room temperature, i.e. at $28^{\circ} \mathrm{C}$, and without any applied load $\left(\varepsilon / \varepsilon_{0}=0\right)$. The same averaging procedure was again used to increase signal to noise ratio.

\section{Coupled influence of temperature and bending loads}

\subsection{Effect of the glass transition temperature of the bonding layer}

The glass transition temperature of the glue used is of $55^{\circ} \mathrm{C}$. This means that in practice, the shear modulus of the glue will decrease drastically above $55^{\circ} \mathrm{C}$. Regarding the EM signature, it is therefore expected that as the temperature increases, the modulus diminishes, and the piezoelectric element becomes less and less coupled to its host structure. As the EM signatures of both piezoelectric elements are available for all the temperatures, this point has been investigated experimentally. Fig. 2(a) and 2(b) show the susceptance for both piezoelectric elements when free or when bonded are presented for temperatures below and above the glass transition temperature. It can be seen that as the temperature increases, the susceptance of both bonded piezoelectric elements tends towards the susceptance of the free piezoelectric elements. In particular, the peaks on the free element's response (noted $A$ on the plots) and on the bonded element (noted $B$ ) get closer to one another. This demonstrates experimentally that when crossing the glass transition temperature of the adhesive being used, the piezoelectric elements gradually decouple from their host structures.

\subsection{Metric for damage detection}

The influence of the simulated damage on the RMSD, as defined by Eq. 2 and computed between $f_{a}=20 \mathrm{kHz}$ and $f_{b}=40 \mathrm{kHz}$, is shown for both piezoelectric elements in Figs. 3(a) and 3(b). These frequency bounds have been chosen here as this frequency range appears to be the most sensitive to the presence of damage for the current setup. From these figures it can be seen that as expected, the introduction of the added mass increases the RMSD. Furthermore, it can be observed that the RMSD does not appear here to be systematically correlated to the weight of the added mass or its position. Nevertheless, these figures indicate that " 2 " is an order of magnitude for the variations of RMSD that can be expected in presence of damage for the present configuration. This value will serve as a basis to assess the influence of temperature and bending 

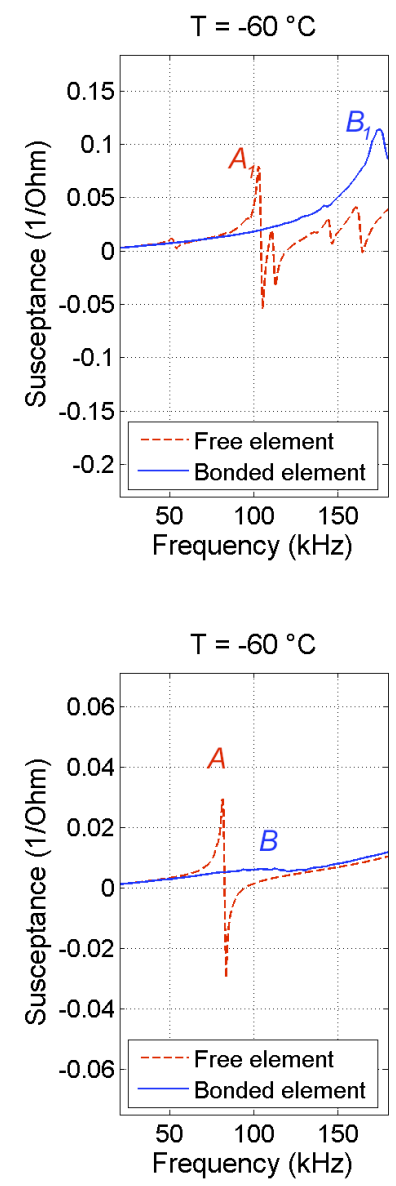
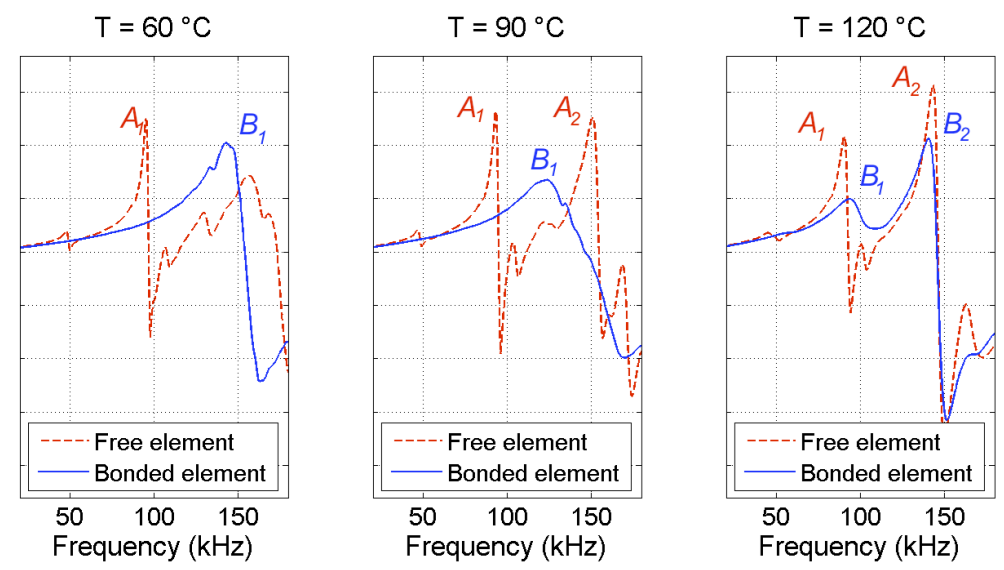

(a) MFC
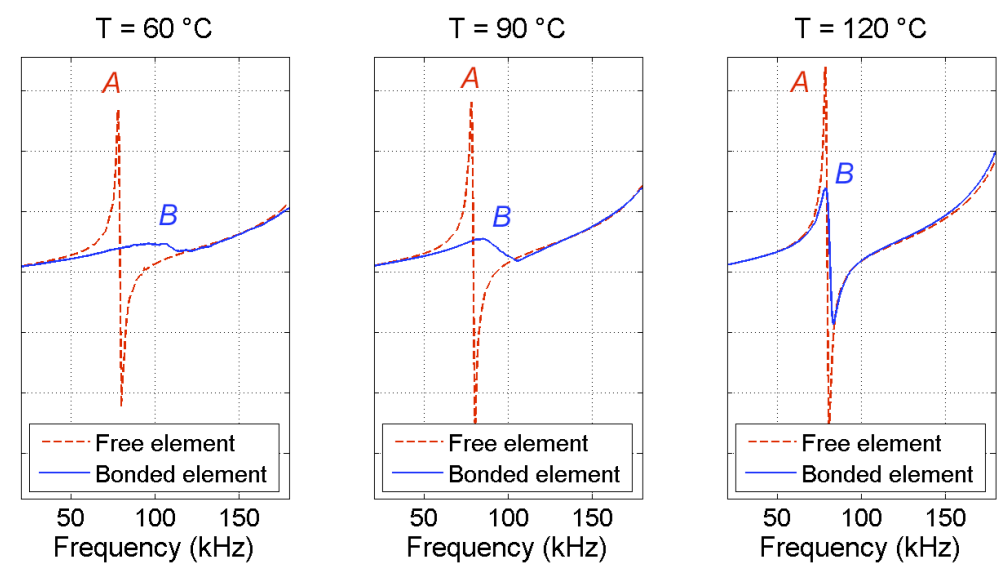

(b) PZT

Fig. 2. Gradual decoupling of the piezoelectric elements with temperature increase below and above the adhesive glass transition temperature $\left(55^{\circ} \mathrm{C}\right)$.

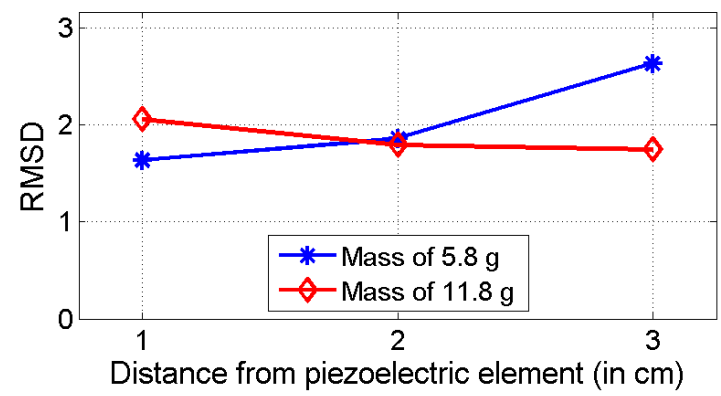

(a) MFC

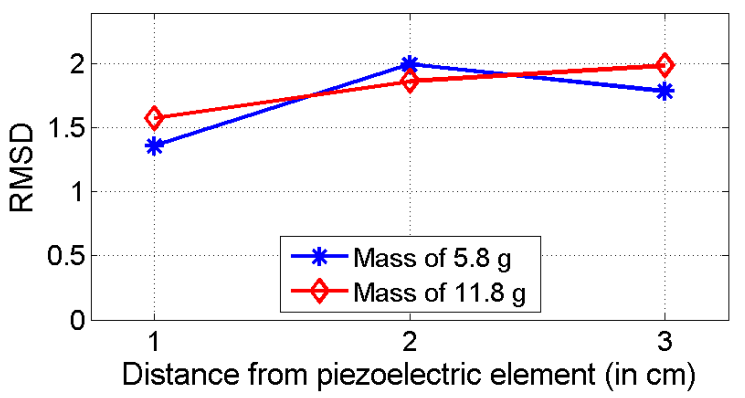

(b) PZT

Fig. 3. Influence of simulated damages on the RMSD.

load.

The coupled influence of bending load and temperature on the RMSD is shown in Figs. 4(a) and 4(b). As the RMSD is a relative metric, the resistance at $T=30^{\circ} \mathrm{C}$ and $\varepsilon / \varepsilon_{0}=0$ has been chosen as reference. The corresponding point in the $\left(T, \varepsilon / \varepsilon_{0}\right)$ plane is indicated in Fig. 4(b) by a black star and the corresponding temperature by a vertical line. From those figures, it can be seen that both factors have a non-negligible influence on the RMSD. The RMSD is increasing as the temperature differs from the reference $30^{\circ} \mathrm{C}$. For temperatures below $30^{\circ} \mathrm{C}$, the bending load induces an RMSD increase whereas above its influence is negligible. The influence of static load below $30^{\circ} \mathrm{C}$ is more pronounced and more regular for the MFC than for the PZT. For both piezoelectric elements, the fact that the RMSD is less sensitive to the bending load 
above $30^{\circ} \mathrm{C}$ than below can be again linked with the fact that the piezoelectric elements seem to be decoupled from their host structures above the glass transition temperature of the glue as illustrated previously. Finally, when comparing the order of magnitudes of the variations of RMSD due to damage $(\simeq 2)$ to the ones due to temperature and bending load $(\simeq 30)$, it can be said that techniques able to compensate for or to take into account both factors are needed in order to perform a reliable damage detection on the basis of RMSD.

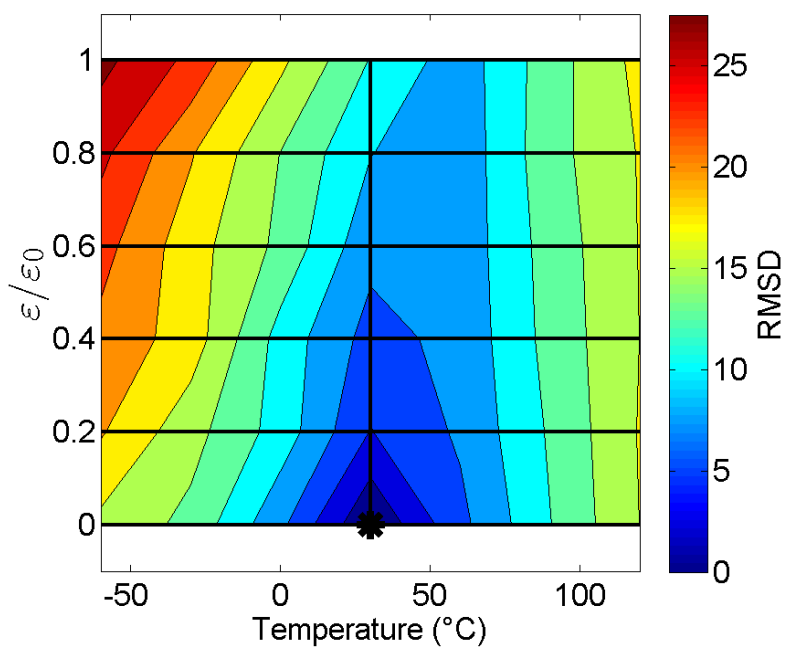

(a) MFC

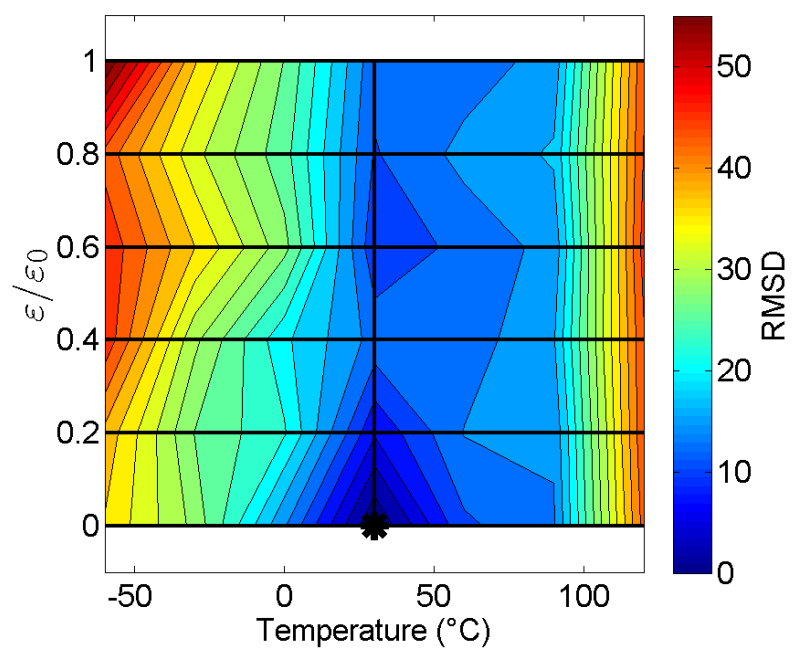

(b) PZT

Fig. 4. Coupled influence of bending load and temperature on the RMSD for (a) MFC and (b) PZT. Reference resistance at $T=30^{\circ} \mathrm{C}$ and $\varepsilon / \varepsilon_{0}=0$ indicated by a black star and a vertical temperature line.

\subsection{Metric for sensor diagnostics}

For the configuration tested here, the decrease of static capacity (as defined by Eq. 3 and computed between $f_{a}=20 \mathrm{kHz}$ and $f_{b}=40 \mathrm{kHz}$ ) due to debonding at ambient temperature is $\Delta C^{\mathrm{s}}=3.3 \mathrm{nF}$ for the PZT and $\Delta C^{\mathrm{s}}=11.8 \mathrm{nF}$ for the MFC. This thus allows to say that an order of magnitude of the variations of static capacity that can be expected in presence of sensor debonding for the present configuration is around $\simeq 10 \mathrm{nF}$. This value will then serve as a basis to assess the importance of the influence of temperature and bending load on the static capacity.

The coupled influence of bending load and temperature on the static capacity is shown for both piezoelectric elements in Figs. 5(a) and 5(b). From those figures, it can be seen that both factors have an influence on the static capacity. For temperatures below $60^{\circ} \mathrm{C}$, the bending load has the effect of decreasing the static capacity whereas above its influence is negligible. The influence of static load below $30^{\circ} \mathrm{C}$ is more pronounced for the MFC than for the PZT. The fact that the static capacity is less sensitive to the bending load above $50^{\circ} \mathrm{C}$ than below can be again linked with the fact that the piezoelectric elements seem to be decoupled from their host structures above the glass transition temperature of bonding layer. Finally, when comparing the order of magnitudes of the variations of static capacity due to debonding $(\simeq 10 \mathrm{nF})$ to the ones due to temperature and bending load $(\simeq 20 \mathrm{nF})$, it can be stated that techniques able to compensate for or to take into account both factors are needed in order to perform a reliable sensor diagnostic on the basis of static capacity.

The static capacity for the free piezoelectric elements have also been computed as a function of temperature and are shown in Figs. 5(a) and 5(b) under the label "Free". Again, the general trend is that the static capacity increases with temperature. When comparing the static capacities for the free piezoelectric elements and for the bonded ones at $\varepsilon / \varepsilon_{0}=0$, one can notice that when bonding a PZT to its host structure, its static capacity decreases as predicted by the theory [2, $11,29,30]$. This static capacity decrease is proportional to the coupling coefficient of the piezoelectric element with the host structure. However this decrease appears to be temperature dependent for the PZT, highlighting again the fact that the coupling of the piezoelectric element with the structure is badly affected by temperature.

\section{Conclusion}

This paper presents experimentations conducted to investigate the simultaneous influence of static load and temperature on the damage detection and sensor self diagnostics metrics of two kinds of piezoelectric components (PZT: lead zirconate 


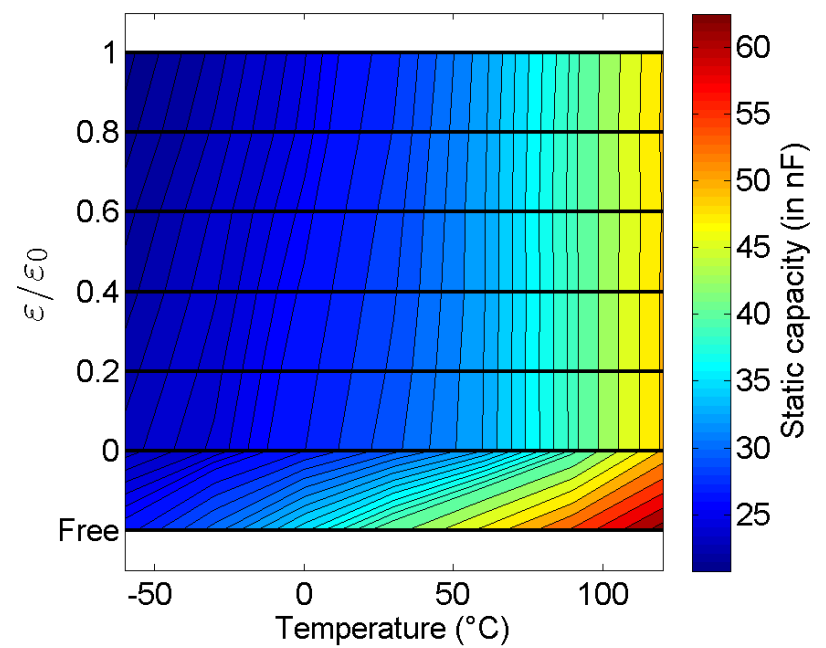

(a) MFC

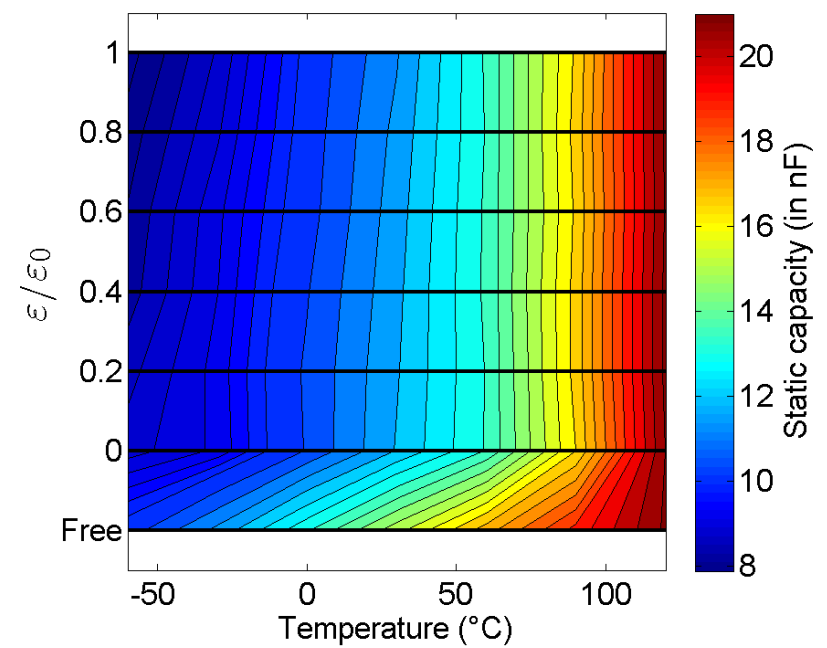

(b) PZT

Fig. 5. Coupled influence of bending load and temperature on the static capacity for both piezoelectric elements. The line labelled "Free" corresponds to the case where the piezoelectric elements have not been bonded to their host-structure.

titanate, and MFC: macro fiber composite) that have been bonded on sandwich composite materials, for the full range of real-life conditions encountered in aeronautics. Obtained results are summarized below:

For both piezoelectric elements, the metrics for damage detection and sensor diagnostics are affected in a coupled manner by both static load and temperature below the glass transition temperature of the adhesive being used. For the chosen configuration, this influence is shown to be higher than the influence of damage or of sensor debonding. Therefore, both the temperature and the static load should be accounted for simultaneously in order to design reliable structural health monitoring systems based on EM signatures.

When bonding piezoelectric elements, adhesives should be chosen carefully. Indeed, below the glass transition temperature the piezoelectric elements are effectively coupled to their host structures but this coupling degrades drastically above this temperature. The glass transition temperature of the adhesive being used for a specific structural health monitoring application must thus be compatible with the expected temperature range.

No substantial differences exist between the behavior of PZT and MFC when subjected to static load and temperature variations. PZT appear to be slightly less sensitive than the MFC to static loads. MFC are very attractive because they can be conformed unto curved surfaces, and, despite of their structural complexity, their behavior appears to be comparable to that of PZT.

This study thus provides additional experimental insight into the combined effects of static load and temperature on the electromechanical signature of piezoelectric elements bonded to aeronautic structures. Although it remains difficult to assess the origin of this coupling of the basis of solely experimental results, some qualitative interpretations are proposed. Current work is focusing on numerical models that are able to reproduce experimental results provided here both qualitatively and quantitatively. Such models should give better understanding and quantification for this coupling and provide ways, if any, to minimize or to compensate for it.

\section{Acknowledgments}

The authors would like to thank Galle Labache for carrying out the differential scanning calorimetry test and Yoann Poirier for his help with the experiments. The specimens tested here were provided by aircraft nacelle manufacturer Aircelle (Safran). This study was partially funded by project CORALIE (CORAC/EPICE).

\section{References}

[1] Park, G., Sohn, H., Farrar, C. R., and Inman, D. J., 2003. "Overview of piezoelectric impedance-based health monitoring and path forward". Shock and vibration digest, 35, pp. 451-463.

[2] Park, S., Park, G., Yun, C. B., and Farrar, C. R., 2009. "Sensor self-diagnosis using a modified impedance model for 
active sensing-based structural health monitoring”. Structural Health Monitoring-an International Journal, 8(1), Jan., pp. 71-82.

[3] Annamdas, V. G. M., and Soh, C. K., 2010. "Application of electromechanical impedance technique for engineering structures: Review and future issues". Journal of Intelligent Material Systems and Structures, 21(1), Jan., pp. 41-59.

[4] Annamdas, V. G. M., and Radhika, M. A., 2013. "Electromechanical impedance of piezoelectric transducers for monitoring metallic and non-metallic structures: A review of wired, wireless and energy-harvesting methods". Journal of Intelligent Material Systems and Structures, 24(9), pp. 1021-1042.

[5] Yang, Y. W., Lim, Y. Y., and Soh, C. K., 2008. "Practical issues related to the application of the electromechanical impedance technique in the structural health monitoring of civil structures: I. experiment". Smart Materials \& Structures, 17(3), June, p. 035008.

[6] Qing, X. L. P., Beard, S. J., Kumar, A., Sullivan, K., Aguilar, R., Merchant, M., and Taniguchi, M., 2008. "The performance of a piezoelectric-sensor-based shm system under a combined cryogenic temperature and vibration environment". Smart Materials \& Structures, 17(5), Oct., p. 055010.

[7] Lin, B., Giurgiutiu, V., Pollock, P., Xu, B. L., and Doane, J., 2010. "Durability and survivability of piezoelectric wafer active sensors on metallic structure". AIAA Journal, 48(3), Mar., pp. 635-643.

[8] Yang, Y., and Miao, A., 2008. "Effect of external vibration on pzt impedance signature". Sensors, 8(11), Nov., pp. 6846-6859.

[9] Sepehry, N., Shamshirsaz, M., and Bastani, A., 2011. "Experimental and theoretical analysis in impedance-based structural health monitoring with varying temperature". Structural Health Monitoring-an International Journal, 10(6), Nov., pp. 573-585.

[10] Overly, T. G., Park, G., Farinholt, K. M., and Farrar, C. R., 2009. "Piezoelectric active-sensor diagnostics and validation using instantaneous baseline data". IEEE Sensors Journal, 9(11), Nov., pp. 1414-1421.

[11] Grisso, B. L., and Inman, D. J., 2010. "Temperature corrected sensor diagnostics for impedance-based SHM". Journal of Sound and Vibration, 329(12), June, pp. 2323-2336.

[12] Koo, K. Y., Park, S., Lee, J. J., and Yun, C. B., 2009. "Automated impedance-based structural health monitoring incorporating effective frequency shift for compensating temperature effects". Journal of Intelligent Material Systems and Structures, 20(4), Mar., pp. 367-377.

[13] Zhou, D., Kim, J. K., Ha, S. H., Quesenberry, J. D., and Inman, D. J., 2009. "A system approach for temperature dependency of impedance-based structural health monitoring". In Smart Sensor Phenomena, Technology, Networks, and Systems.

[14] Balmes, E., Guskov, M., Rebillat, M., and Mechbal, N., 2014. "Effects of temperature on the impedance of piezoelectric actuators used for SHM". In 14th Symposium on Vibration, Shock and Noise (VISHNO), pp. 1-6.

[15] Baptista, F. G., Budoya, D. E., de Almeida, V. A. D., and Ulson, J. A. C., 2014. "An experimental study on the effect of temperature on piezoelectric sensors for impedance-based structural health monitoring". Sensors, 14(1), pp. 12081227.

[16] Buethe, I., Eckstein, B., and Fritzen, C. P., 2014. "Model-based detection of sensor faults under changing temperature conditions". Structural Health Monitoring, 13(2), pp. 109-119.

[17] Stancalie, A., Sporea, D., Malinowski, P., Mieloszyk, M., Opoka, S., Wandowski, T., and Ostachowicz, W., 2015. "Influence of support conditions and temperature on the emi characteristics". In Journal of Physics: Conference Series, Vol. 628, IOP Publishing, p. 012112.

[18] Annamdas, V. G. M., Yang, Y. W., and Soh, C. K., 2007. "Influence of loading on the electromechanical admittance of piezoceramic transducers". Smart Materials \& Structures, 16(5), Oct., pp. 1888-1897.

[19] Lim, Y. Y., and Soh, C. K., 2012. "Effect of varying axial load under fixed boundary condition on admittance signatures of electromechanical impedance technique". Journal of Intelligent Material Systems and Structures, 23(7), May, pp. 815-826.

[20] Phillips, R., Zhu, X., and di Scalea, F. L., 2012. "The influence of stress on electro-mechanical impedance measurements in rail steel". Materials Evaluation, 70(10), Oct., pp. 1213-1218.

[21] Radhika, M., and Annamdas, V., 2013. Experimental studies on structural load monitoring using piezoelectric transducer based electromechanical impedance method.

[22] Yang, J., Zhu, H., Wang, D., and Ai, D., 2015. "The compensation technique of tensile force effect on the electromechanical impedance method for structural health monitoring". Journal of Intelligent Material Systems and Structures, p. 1045389X14568879.

[23] Lim, H. J., Kim, M. K., Sohn, H., and Park, C. Y., 2011. "Impedance based damage detection under varying temperature and loading conditions". Ndt \& E International, 44(8), Dec., pp. 740-750.

[24] Zhu, X., Phillips, R., and Lanza di Scalea, F., 2013. "Axial stress determination using impedance-based method and its application on the thermal stresses measurement in continuous welded rail". pp. 86951N-86951N.

[25] Zhu, X., Lanza di Scalea, F., and Fateh, M., 2015. "On the study of the influences of temperature and axial load to the impedance-based structural health monitoring system". In 11th International Workshop on Advanced Materials and 
Smart Structures Technology, University of Illinois Urbana-Champaign.

[26] Xu, D., Banerjee, S., Wang, Y., Huang, S., and Cheng, X., 2015. "Temperature and loading effects of embedded smart piezoelectric sensor for health monitoring of concrete structures". Construction and Building Materials, 76, pp. 187-193.

[27] Giurgiutiu, V., and Zagrai, A., 2005. "Damage detection in thin plates and aerospace structures with the electromechanical impedance method”. Structural Health Monitoring-an International Journal, 4(2), June, pp. 99-118.

[28] Liu, X. H., 2009. "Robust damage metric in terms of magnitude and phase for impedance based structural health monitoring. (vol 8, pg 303, 2009)". Structural Health Monitoring-an International Journal, 8(6), Nov., pp. $573-573$.

[29] Giurgiutiu, V., and Zagrai, A. N., 2002. "Embedded self-sensing piezoelectric active sensors for on-line structural identification". Journal of Vibration and Acoustics-transactions of the Asme, 124(1), Jan., pp. 116-125.

[30] Park, G., Farrar, C. R., Rutherford, A. C., and Robertson, A. N., 2006. "Piezoelectric active sensor self-diagnostics using electrical admittance measurements". Journal of Vibration and Acoustics-transactions of the Asme, 128(4), Aug., pp. 469-476.

[31] Mulligan, K. R., Quaegebeur, N., Ostiguy, P. C., Masson, P., and Letourneau, S., 2013. "Comparison of metrics to monitor and compensate for piezoceramic debonding in structural health monitoring". Structural Health Monitoringan International Journal, 12(2), Mar., pp. 153-168.

[32] Peairs, D. M., Park, G., and Inman, D. J., 2004. "Improving accessibility of the impedance-based structural health monitoring method”. Journal of Intelligent Material Systems and Structures, 15(2), Feb., pp. 129-139. 